\title{
Evaluación de ovitrampas para vigilancia y control de Aedes aegypti en dos centros urbanos del Urabá antioqueño
}

\author{
Érika Patricia Alarcón'1, Ángela María Segura², Guillermo Rúa-Uribe ${ }^{3}$, Gabriel Parra-Henao ${ }^{1,2}$ \\ 1 Instituto Colombiano de Medicina Tropical, Universidad CES, Sabaneta, Colombia \\ 2 Grupo de Epidemiología y Bioestadística, Universidad CES, Sabaneta, Colombia \\ ${ }^{3}$ Grupo de Entomología Médica, Universidad de Antioquia, Medellín, Colombia \\ Lugar donde se realizó el trabajo: municipios de Apartadó y Carepa, Antioquia, e Instituto Colombiano de \\ Medicina Tropical-CES
}

Introducción. Aedes (Stegomyia) aegypti es el principal vector del dengue. En el control del mosquito se han usado insecticidas químicos contra los cuales ha desarrollado resistencia. Es necesaria la evaluación de estrategias alternativas que sean eficientes, económicas y de fácil aplicación, como las ovitrampas con Bacillus thuringiesis var. israeliensis.

Objetivo. Evaluar el impacto de ovitrampas con B. thuringiesis var. israeliensis sobre los índices aédicos tradicionales, como estrategia para la vigilancia y el control de $A$. aegypti.

Materiales y métodos. Se seleccionaron ocho barrios de los municipios de Apartadó y Carepa, Antioquia, de los cuales se escogieron dos barrios para la intervención y dos para el control en cada municipio. La intervención consistió en la instalación de una ovitrampa con $B$. thuringiesis var. israeliensis en cada una de las viviendas. Las ovitrampas se visitaron mensualmente entre septiembre de 2009 y marzo de 2010. Se obtuvieron los índices aédicos tradicionales y se hicieron comparaciones entre los barrios. Se calculó el índice de ovitrampas positivas y el de densidad de huevos, y se generaron los mapas de densidad.

Resultados. Se colocaron 519 ovitrampas muestreadas mensualmente. Se hicieron 3.114 muestreos, con un porcentaje de registros positivos de 76,4 \%. Se recolectaron 501.425 huevos. En Apartadó se observaron diferencias significativas entre el índice de infestación de viviendas, el índice de infestación de depósitos y el índice de Breteau en los barrios intervenidos comparados con los barrios de control. El índice de ovitrampas positivas evidenció un alto riesgo de infestación por $A$. aegypti y, los índices tradicionales, niveles de riesgo medio y bajo.

Conclusiones. Las ovitrampas tuvieron impacto sobre los índices tradicionales y demostraron ser estrategias útiles en la vigilancia de $A$. aegypti en el Urabá antioqueño.

Palabras clave: Aedes aegypti, Bacillus thuringiensis, dengue, insectos vectores, Colombia.

http://dx.doi.org/10.7705/biomedica.v34i3.2134

Ovitraps evaluation for surveillance and control of Aedes aegypti in two urban settlements of Urabá, Antioquia

Introduction: Aedes (Stegomyia) aegypti is the main vector of dengue. Chemical insecticides have been used to control the mosquito and it has developed resistance. It is necessary to evaluate alternative strategies that are efficient, economical and easy to apply, such as ovitraps with Bacillus thuringiesis israeliensis.

Objective: To evaluate the impact of ovitraps loaded with $B$. $t$. israeliensis on traditional indexes, as strategies for surveillance and control of $A$. aegypti.

Materials and methods: We selected eight neighborhoods from the municipalities of Apartadó and Carepa. Two neighborhoods in each municipality were chosen for intervention and two for control. The intervention consisted in the installation of ovitraps with $B$. $t$. israeliensis in every house. The traps were visited each month between September, 2009, and March, 2010. Traditional indexes were obtained and compared among the neighborhoods. Ovitrap positivity index and egg density index were calculated and we generated density maps.

Results: Five hundred and nineteen ovitraps were placed monthly; 3,114 samples were obtained, from which $76.4 \%$ were positive. We collected 501,425 eggs. In Apartadó, statistically significant differences

\section{Contribución de los autores:}

Gabriel Parra-Henao: análisis de datos, edición y corrección del artículo

Érika Patricia Alarcón: recolección de la información en campo y laboratorio, análisis de datos y escritura del artículo

Ángela María Segura: análisis de datos

Guillermo Rúa-Uribe: edición y corrección del artículo 
were observed in the house, container and Breteau indexes. The ovitrap positivity index showed high risk of $A$. aegypti infestation and traditional indexes showed medium and low risk levels.

Conclusions: Ovitraps had an impact on traditional indexes and proved to be useful strategies for surveillance and control of $A$. aegypti in Urabá, Antioquia.

Key words: Aedes aegypti, Bacillus thuringiensis, dengue, insect vectors, Colombia. http://dx.doi.org/10.7705/biomedica.v34i3.2134

Aedes (Stegomyia) aegypti Linnaeus, 1762 (Diptera: Culicidae) es una especie hematófaga, vector del virus del dengue y de la fiebre amarilla urbana. Es una especie antropofílica adaptada a ambientes urbanos, particularmente a viviendas humanas $(1,2)$. Se encuentra en casi el $80 \%$ del territorio colombiano situado en zonas por debajo de 2.200 msnm $(3,4)$. Durante la década de 1960 se consideró que este vector se había erradicado en nuestro país, gracias a las campañas verticales de control de larvas y adultos. Hoy, sin embargo, gran parte del territorio está infestado de nuevo (3).

De todas las enfermedades virales transmitidas por vectores al hombre, el dengue se considera la más importante debido a las altas tasas de morbilidad y mortalidad que conlleva (5-8).

El dengue es un problema de salud pública que afecta a los países tropicales, entre ellos Colombia. La dispersión y la persistencia de esta enfermedad se debe, principalmente, al rápido crecimiento demográfico, al desplazamiento de la población rural hacia las cabeceras municipales, a la urbanización incontrolada, que propicia la proliferación de criaderos, y a medidas de control del mosquito inadecuadas o poco eficientes (9-12).

Al menos la mitad de la población mundial vive en áreas de alto riesgo. Cada año se presentan de 50 a 100 millones de casos nuevos en el mundo, de los cuales 500.000 corresponden a dengue grave $y$ de estos, 25.000 son letales (13-15).

En Colombia el comportamiento del dengue es endémico con periodos epidémicos. Durante los últimos 20 años se han registrado ciclos epidémicos cada tres a cinco años, así como el aumento del número y la frecuencia de los brotes y de la mortalidad por esta causa. Cerca de 25 millones de habitantes de las zonas urbanas con transmisión endémica en el país, están en riesgo de adquirir la enfermedad (4).

\footnotetext{
Correspondencia:

Gabriel Parra-Henao, Instituto Colombiano de Medicina Tropical, Universidad CES, Carrera 43 A N ${ }^{\circ}$ 52S-99, Sabaneta, Antioquia Teléfono: (054) 305 3500; fax: (054) 3014258 gparra@ces.edu.co,gparrahenao@gmail.com

Recibido: 23/09/13; aceptado: 05/05/14
}

En el 2010 se registró en el país la mayor epidemia de dengue, durante la cual circularon los cuatro serotipos. Para ese año, se registraron en el Sivigila 157.152 casos, 9.863 de los cuales fueron dengue grave, y 210 muertes, lo que equivale a una letalidad de 2,24\% (4). De estos casos, el 16,4\% se reportó en Antioquia. Durante 2011 y 2012 hubo una disminución notable de casos de dengue y de dengue grave, pero hasta la semana seis del 2013 se observó un incremento significativo de casos comparado con el de los años anteriores, lo que indica que el país se encuentra en una situación de epidemia de dengue (16).

De los 11 municipios del Urabá antioqueño se seleccionaron los de Carepa y Apartadó, ya que allí se desarrolló el proyecto "Abordaje ecosistémico para el control del dengue", del cual hizo parte este estudio. Estos municipios tienen condiciones climáticas y ecológicas propicias para el desarrollo del mosquito $A$. aegypti y en la región se registra anualmente un número importante de casos de dengue. En el 2010 se reportó en el municipio de Carepa una tasa de 134,3 casos de dengue por 100.000 habitantes, en tanto que en Apartadó la tasa fue de 28,7 casos de dengue por 100.000 habitantes (17).

Dado que no hay vacunas ni un método efectivo de control del dengue, se ha establecido que la manera más eficiente de combatir la enfermedad son las estrategias de control del vector (18-20), algunas de las cuales se fundamentan en el uso de insecticidas (14). La presión química ejercida sobre las poblaciones de $A$. aegypti ha generado resistencia en las poblaciones del mosquito en 41 países de América y el Caribe (21-24), así como en otros lugares del mundo $(25,26)$, y se estima que la especie es resistente a 24 compuestos químicos diferentes (26).

El aumento de casos de dengue en el país durante los últimos años permite concluir que las medidas implementadas por los programas de vigilancia y control vectorial han sido poco efectivas y han tenido poco impacto sobre las poblaciones de $A$. aegypti, razón por la cual es necesario manejar el control de los vectores con estrategias alternativas 
basadas en medidas sencillas que la comunidad pueda aplicar y que sean sostenibles a largo plazo, como es el caso de las ovitrampas.

En países como Brasil, Cuba y Costa Rica se ha implementado con buenos resultados el uso de ovitrampas como un método alternativo para la vigilancia y el control de $A$. aegypti, pues con ellas se detecta la presencia del vector en menor tiempo que con los índices tradicionales $(27,28)$. Algunas ovitrampas han sido modificadas y convertidas en trampas letales utilizando productos químicos de efecto knockdown para adultos de A. aegypti (29). Perich, et al., (29) evaluaron ovitrampas letales que contenían telas impregnadas con deltametrina y encontraron que estas disminuían significativamente las poblaciones de $A$. aegypti en las viviendas intervenidas. En Tailandia, Sithiprasasna, et al., (30) evaluaron las ovitrampas letales para el control de $A$. aegypti y determinaron que su empleo, además de la eliminación de los criaderos, podía reducir las poblaciones del mosquito. Regis, et al., (31) evaluaron ovitrampas que contenían el larvicida biológico Bacillus thuringiensis var. israelensis y demostraron que servían como herramientas de control, pues su uso disminuyó la densidad de mosquitos y produjo la muerte de las larvas inmediatamente después de la eclosión de los huevos. Bacillus thuringiesis var. israeliensis no interfiere con la oviposición, por el contrario, estimula dicho proceso $(32,33)$, por lo que estos autores sugieren que las ovitrampas son herramientas de bajo costo, no son contaminantes porque no utilizan productos químicos, y pueden emplearse en estrategias integradas de control (34-36).

La presente investigación se desarrolló con el fin de evaluar las ovitrampas con $B$. thuringiesis var. israeliensis como una estrategia para la vigilancia y el control de $A$. aegypti en los municipios de Apartadó y Carepa, Colombia.

\section{Materiales y métodos}

\section{Área de estudio}

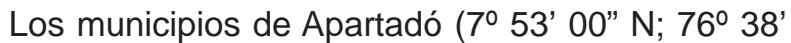
$00^{\prime \prime}$ O) y de Carepa (7․ 45' 00" N; 76 $39^{\prime} 00^{\prime \prime}$ O) se localizan en la región del Urabá antioqueño, al noroccidente del departamento de Antioquia, Colombia (figura 1). Su altura sobre el nivel del mar es de 25 y $28 \mathrm{~m}$, respectivamente, las temperaturas

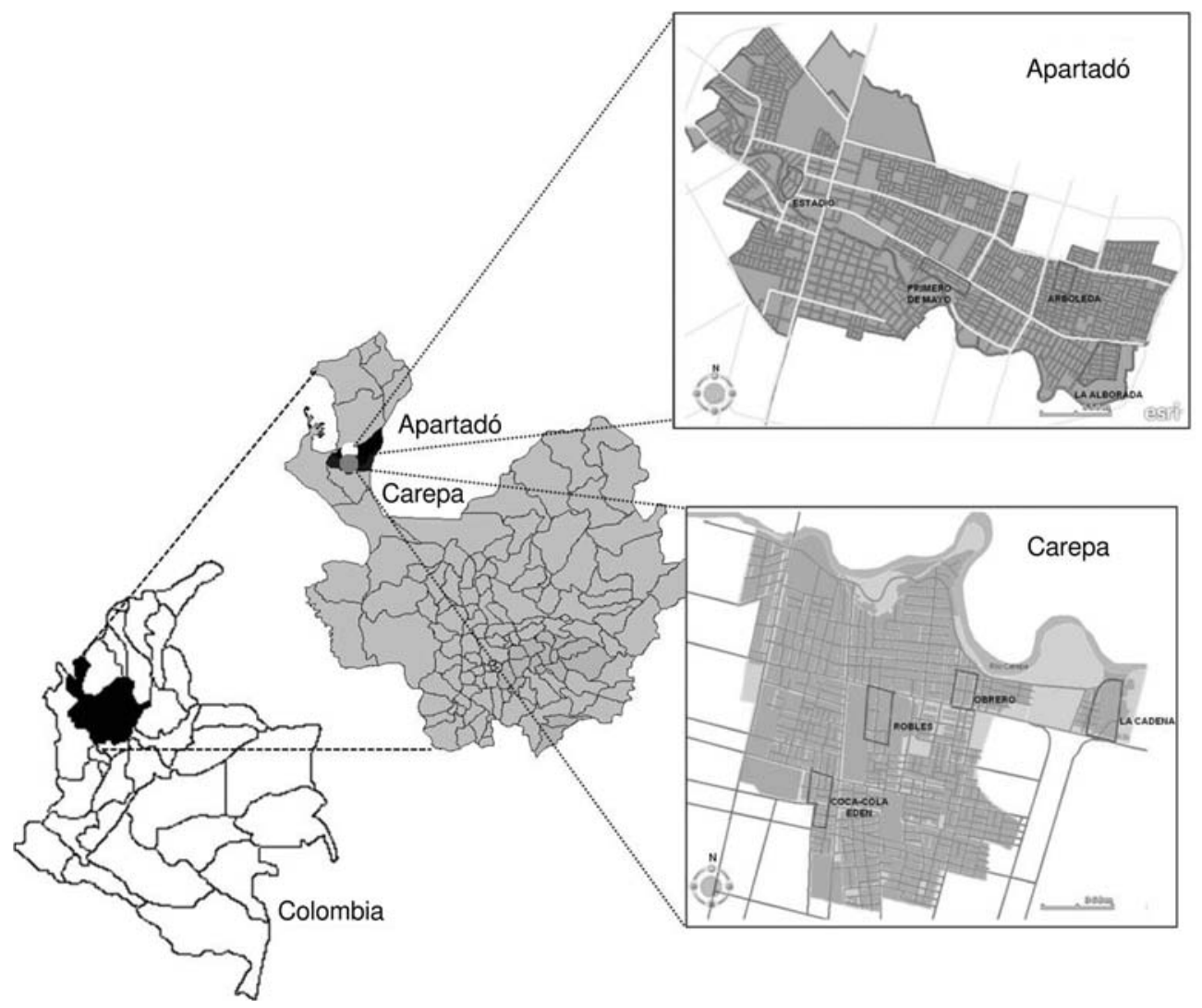

Figura 1. Ubicación de los barrios estudiados (en rojo), municipios de Apartadó y Carepa, Antioquia, Colombia 
fluctúan entre los 20 y los $35^{\circ} \mathrm{C}$ y la humedad relativa promedio es de $88 \%$. De acuerdo con el último reporte de población (2010), la población urbana de Apartadó y Carepa es de 127.678 y 49.953 habitantes, respectivamente $(37,38)$.

\section{Diseño del estudio}

Con base en los registros de las secretarías de salud de los municipios del estudio, se seleccionaron aleatoriamente ocho barrios de alta incidencia de infestación por $A$. aegypti (cuatro barrios por municipio) en las cabeceras municipales. En dos de los barrios seleccionados en cada municipio se efectuó la intervención y los otros dos se consideraron controles. La descripción de los barrios estudiados se presenta en el cuadro 1.

La estrategia de intervención, que se extendió desde septiembre de 2009 hasta marzo de 2010, consistió en la colocación de una ovitrampa con $B$. thuringiesis var. israeliensis en cada una de las viviendas de los barrios intervenidos (519 viviendas en total) (cuadro 2). En los barrios de control no se hizo intervención. Tanto en los barrios intervenidos como en los de control, se hicieron levantamientos mensuales de los índices de vivienda, de depósito, de Breteau y de adultos, como se explica más adelante, y se clasificaron de acuerdo con los parámetros de la Organización Mundial de la Salud (OMS) (cuadro 3).

\section{Trampas de oviposición}

Las ovitrampas se elaboraron con envases de polietileno (PET®) reciclados, los cuales se cortaron para obtener una dimensión de $20 \mathrm{~cm}$ de largo por $13 \mathrm{~cm}$ de diámetro y una capacidad de 2 litros; posteriormente, la parte externa se pintó de color negro. El perímetro interno del recipiente se cubrió con un pedazo de tela de color blanco de $12 \mathrm{~cm}$ de largo por $15 \mathrm{~cm}$ de ancho, el cual sirvió de sustrato de oviposición. Se usó tela blanca para facilitar la visualización y el conteo de los huevos (figura 2). Posteriormente, en cada ovitrampa se pusieron $1,5 \mathrm{~L}$ de agua potable y $1 \mathrm{~g}$ de $B$. thuringiesis var. israeliensis granulado para así garantizar que la permanencia de las trampas en las viviendas durante un mes no las convirtiera

Cuadro 1. Descripción de los barrios estudiados (datos proporcionados por la Dirección Seccional de Salud de Antioquia y la Alcaldía de Apartadó, Secretaría de Planeación y Ordenamiento Territorial, 2013).

\begin{tabular}{|c|c|c|c|c|c|c|c|c|}
\hline \multirow[t]{2}{*}{ Municipio } & \multirow[t]{2}{*}{ Barrio } & \multirow{2}{*}{$\begin{array}{c}\text { Densidad } \\
\text { demográfica } \\
\text { (habitantes) }\end{array}$} & \multirow{2}{*}{$\begin{array}{c}\text { Estrato } \\
\text { socio- } \\
\text { económico }\end{array}$} & \multirow[t]{2}{*}{ Ubicación } & \multicolumn{3}{|c|}{$\begin{array}{l}\text { Condiciones físicas } \\
\text { de las viviendas }\end{array}$} & \multirow{2}{*}{$\begin{array}{c}\text { Depósitos de } \\
\text { almacenamiento } \\
\text { de agua }\end{array}$} \\
\hline & & & & & Piso & Techo & Paredes & \\
\hline \multirow[t]{4}{*}{ Apartadó } & La Alborada* & 1.266 & Medio & Urbano & Baldosa & Eternit & Ladrillo & Tanque bajo \\
\hline & Primero de mayo* & 2.922 & Bajo & Urbano & $\begin{array}{l}\text { Tierra o } \\
\text { cemento }\end{array}$ & $\begin{array}{l}\text { Eternit } \\
\text { o cinc }\end{array}$ & $\begin{array}{c}\text { Madera, } \\
\text { plástico, ladrillo }\end{array}$ & Canecas \\
\hline & Arboleda $^{+}$ & 349 & Medio & Urbano & Baldosa & Eternit & Ladrillo & Tanque bajo \\
\hline & Estadio $^{+}$ & 284 & Alto & Urbano & Baldosa & Eternit & Ladrillo & Tanque bajo \\
\hline \multirow[t]{4}{*}{ Carepa } & Cadena* & 761 & Bajo & Semi-urbano & $\begin{array}{c}\text { Tierra o } \\
\text { cemento }\end{array}$ & $\begin{array}{l}\text { Eternit } \\
\text { o cinc }\end{array}$ & $\begin{array}{c}\text { Madera, } \\
\text { plástico, ladrillo }\end{array}$ & $\begin{array}{c}\text { Canecas y } \\
\text { tanque bajo }\end{array}$ \\
\hline & Coca-Cola Edén* & 416 & Medio & Urbano & Baldosa & Eternit & Ladrillo & $\begin{array}{c}\text { Tanque bajo } \\
\text { y canecas }\end{array}$ \\
\hline & Obrero+ ${ }^{+}$ & 503 & Medio & Urbano & Baldosa & Eternit & ladrillo & Tanque bajo \\
\hline & Robles $^{+}$ & 322 & Medio & Urbano & Baldosa & Eternit & ladrillo & Tanque bajo \\
\hline
\end{tabular}

${ }^{*}$ Barrios intervenidos + Barrios de control

Cuadro 2. Distribución de ovitrampas colocadas por barrio en cada municipio

\begin{tabular}{llcc}
\hline Municipio & Barrio & $\begin{array}{c}\text { Número de } \\
\text { ovitrampas } \\
\text { colocadas }\end{array}$ & $\begin{array}{c}\text { Número de } \\
\text { viviendas }\end{array}$ \\
\hline \multirow{2}{*}{ Apartadó } & La Alborada & 197 & 197 \\
\multirow{2}{*}{ Carepa } & Primero de Mayo & 138 & 138 \\
& Cadena & 95 & 95 \\
& Coca-Cola Edén & 89 & 89 \\
\hline \multicolumn{2}{l}{ Total de ovitrampas } & 519 & \\
\hline
\end{tabular}

Cuadro 3. Clasificación del nivel de riesgo según los indicadores entomológicos tradicionales (Dirección Seccional de Salud de Antioquia, 2007)

\begin{tabular}{lccc}
\hline \multirow{2}{*}{ Indicador } & \multicolumn{3}{c}{ Riesgo (\%) } \\
\cline { 2 - 4 } & Bajo & Medio & Alto \\
\hline IV & $<4$ & $4-35$ & $>35$ \\
ID & $<3$ & $3-20$ & $>20$ \\
IB & $<5$ & $5-50$ & $>50$ \\
\hline
\end{tabular}

IV: índice de infestación de viviendas, ID: índice de infestación de depósitos, IB: índice de Breteau 


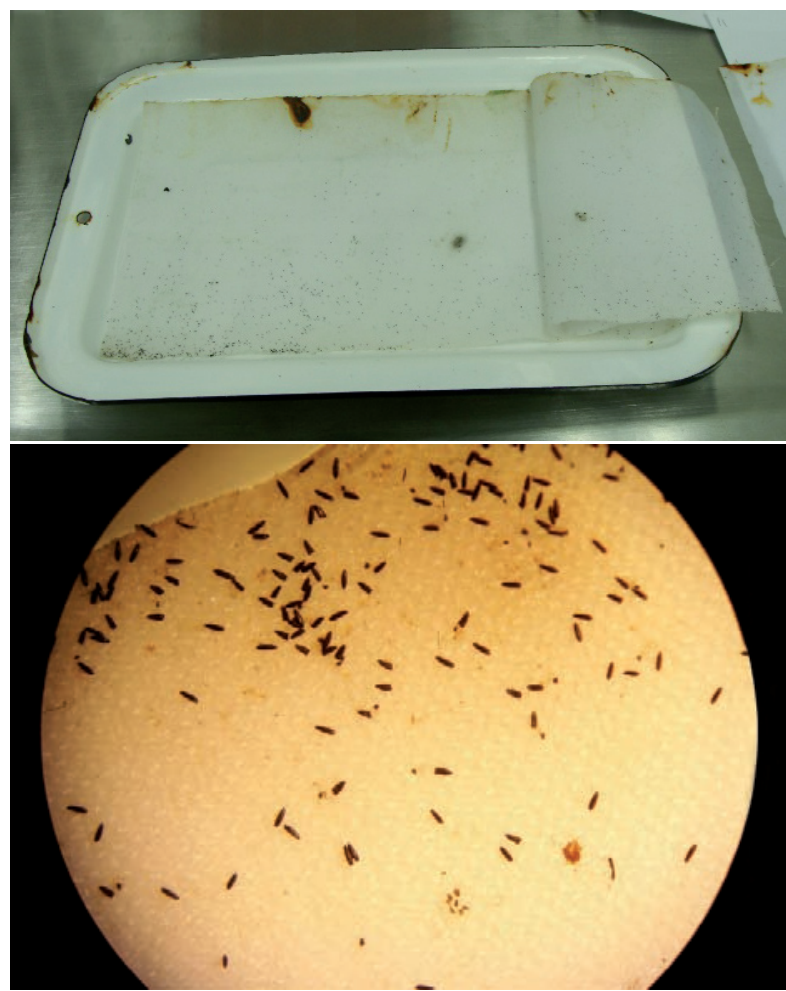

Figura 2. Huevos de Aedes aegypti obtenidos en las ovitrampas

en criaderos de mosquitos, tal como lo describió Acioli (39). Cada ovitrampa se marcó con código de identificación y georreferenciación en el momento de su colocación.

\section{Colocación de las ovitrampas}

Las ovitrampas se colocaron en las viviendas en septiembre de 2009 y se mantuvieron hasta marzo de 2010. Para ponerlas se buscaron lugares en el domicilio o en el peridomicilio que estuvieran cerca de otros recipientes de almacenamiento de agua (tanques bajos o elevados, y pocetas). Se colocaron a una altura no mayor de $1,3 \mathrm{~m}$, en lugares sombreados y protegidos del agua de Iluvia, siguiendo la metodología utilizada por Regis, et al. (31).

\section{Evaluación de las ovitrampas como estrategia de control}

Para la evaluación de las ovitrampas con $B$. thuringiesis var. israeliensis se compararon todos los datos de los índices entomológicos obtenidos en el periodo previo a la intervención y durante esta. El muestreo de viviendas por barrio y el levantamiento de índices se llevaron a cabo de acuerdo con la metodología descrita por la Organización Panamericana de la Salud (OPS) (cuadro 3) (40-
42). Así, en los barrios con 100 viviendas o menos, se muestrearon 45 viviendas y, en los barrios con 101 a 200 viviendas, 51 .

En el procedimiento de selección se enumeraron consecutivamente todas las viviendas, se seleccionó un número inicial al azar y de allí en adelante se hizo el muestreo con base en la siguiente fórmula: número total de viviendas del barrio/número de viviendas por encuestar; este cociente arrojó el número de viviendas que debían omitirse entre una vivienda seleccionada y otra. De esta manera, se cubrió todo el barrio hasta obtener el número de viviendas necesarias para el muestreo.

\section{Levantamiento de índices entomológicos}

Los índices entomológicos se levantaron mensualmente tanto en los barrios intervenidos como en los de control. Se hizo un levantamiento de los índices antes de la intervención y cinco levantamientos mensuales durante la intervención, entre octubre de 2009 y marzo de 2010. Por razones técnicas, en diciembre de 2009 no fue posible levantar los índices, pero sí se inspeccionaron las ovitrampas.

El levantamiento de los índices entomológicos se hizo de la siguiente manera.

Muestreo de larvas y pupas. Se hizo búsqueda activa de larvas y pupas de $A$. aegypti en todos los recipientes que contenían agua, en cada una de las casas. El material recolectado se guardó en viales con alcohol al 70 \% para su preservación.

Muestreo de mosquitos adultos. La captura de mosquitos adultos se hizo en reposo, siguiendo la metodología de la OPS. Los funcionarios del proyecto pedían autorización a los habitantes de la vivienda para la búsqueda minuciosa de adultos de $A$. aegypti en las casas. La búsqueda se llevó a cabo entre las 08:00 y las 17:00 horas, dedicando como mínimo 15 minutos a cada vivienda, e incluyó el peridomicilio (paredes y superficies aledañas a depósitos de agua) y el domicilio (todas las paredes de la casa, objetos colgados y rincones húmedos y oscuros). Se utilizó una linterna para iluminar los sitios oscuros y visualizar los mosquitos adultos, los cuales se capturaron con ayuda de una red entomológica pequeña (de $15 \mathrm{~cm}$ de diámetro) y un capturador bucal. El material recolectado se sacrificó en cámara letal con alcohol al 70 \% y se depositó en frascos plásticos rotulados para cada vivienda.

Todo el material biológico recolectado en este levantamiento se transportó al Laboratorio de Entomología del Instituto Colombiano de Medicina 
Tropical en Medellín, para su posterior identificación con claves taxonómicas especializadas $(43,44)$.

Revisión de las ovitrampas. Las ovitrampas de cada vivienda se revisaban durante la primera semana de cada mes para cambiar la tela, el $B$. thuringiesis var. israeliensis y el agua. Las telas removidas se rotulaban cada una por separado para luego trasladarlas al Laboratorio de Entomología del Instituto Colombiano de Medicina Tropical en Medellín. El conteo de huevos de cada tela se hacía mediante el uso de un estereomicroscopio Nikon SMZ800.

Uso de ovitrampas para la vigilancia de $A$. aegypti. Para evaluar las ovitrampas en la vigilancia de $A$. aegypti, se contaron los huevos de todas las telas retiradas de las ovitrampas. Con estos datos se calculó el índice de densidad de huevos. Los valores de dicho índice se utilizaron para determinar la distribución espacial de huevos de $A$. aegypti y obtener los puntos críticos de mayor densidad del vector, usando mapas de densidad de Kernel y el programa ArcGis 10,0.

\section{Análisis de la información}

Para evaluar las ovitrampas como método de control de $A$. aegypti, se compararon los índices entomológicos (de viviendas, de Breteau y de depósitos) de los barrios tratados y de los barrios de control por medio de la prueba de Friedman, con una significación estadística del $5 \%$. Los índices de infestación de adultos no se incluyeron en el análisis estadístico debido a que la mayoría tuvo valor de cero. Los modelos espaciales se generaron mediante el método de cálculo de densidad de tipo Kernel que, en este caso, consistió en la conversión de los lugares donde se encontraron los huevos en superficies continuas con base en la cantidad de huevos. Esta función permitió crear áreas de densidad de huevos y clasificarlas según su densidad alta, media o baja.

\section{Consideraciones éticas}

A todas las personas de los barrios estudiados se les informó sobre el estudio. Se obtuvo consentimiento informado de la comunidad de los barrios estudiados a través del proyecto "Abordaje ecosistémico para el control del dengue en el Urabá antioqueño", identificado con el código 3256-0418067 de Colciencias, del cual hace parte este estudio. El Comité de Ética de la Universidad CES aprobó el consentimiento informado.

\section{Resultados}

En total se colocaron 519 ovitrampas en los cuatro barrios intervenidos (cuadro 2). Todos los barrios incluidos en el estudio presentaban índices de infestación altos antes de la intervención (figuras 3-6). El municipio de Carepa presentó los valores

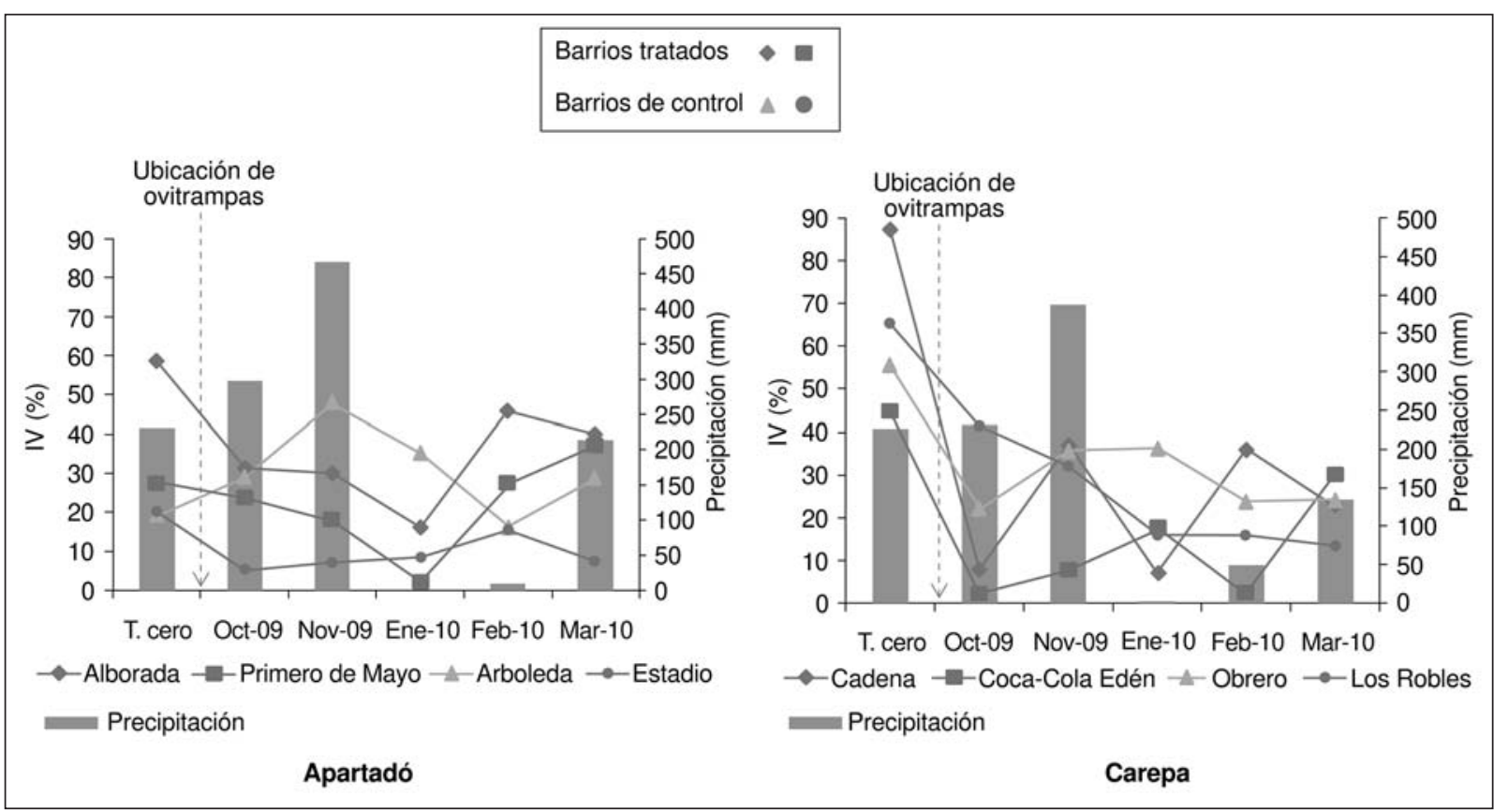

Figura 3. Variación temporal de los índices de infestación de vivienda en los barrios de Apartadó y Carepa, ambos estudiados 


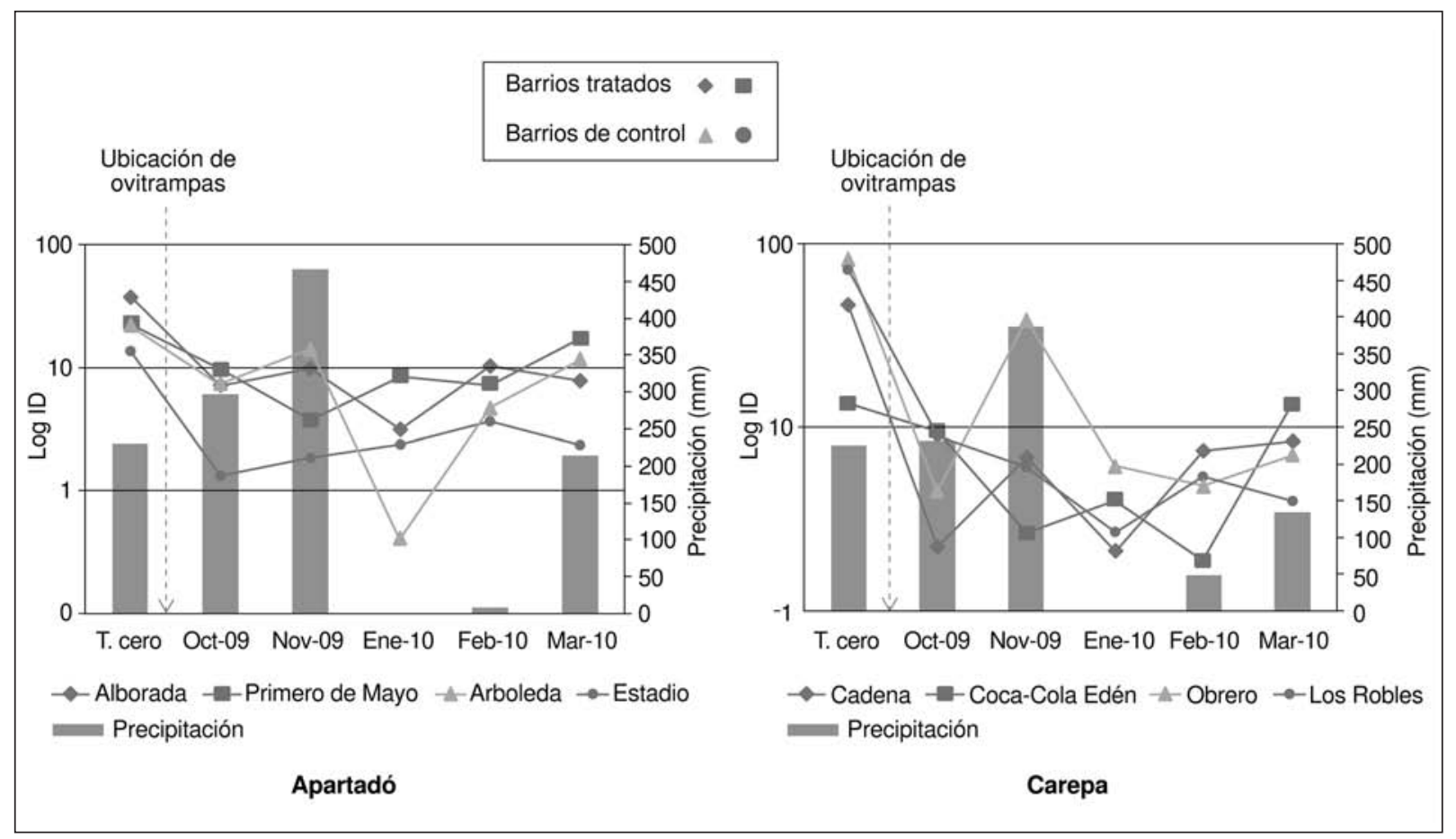

Figura 4. Variación temporal de los índices de infestación de depósitos en los barrios de Apartadó y Carepa, ambos estudiados. La gráfica se presenta en escala logarítmica debido al rango de valores (mínimo, 0,4, y máximo, 83).

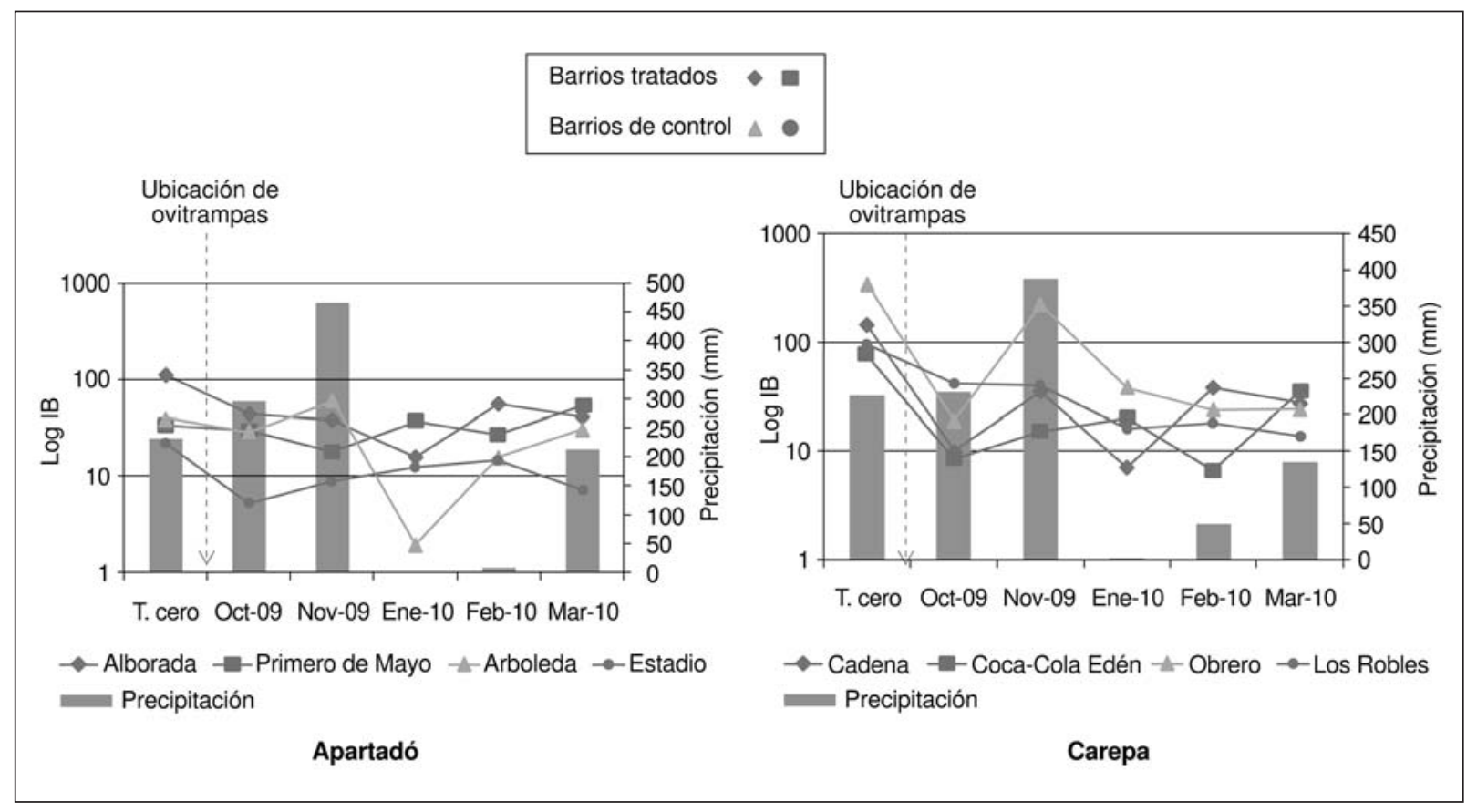

Figura 5. Variación temporal de los índices de Breteau en los barrios de Apartadó y Carepa, ambos estudiados. La gráfica se presenta en escala logarítmica debido al rango de valores (mínimo, 6, y máximo, 338). 


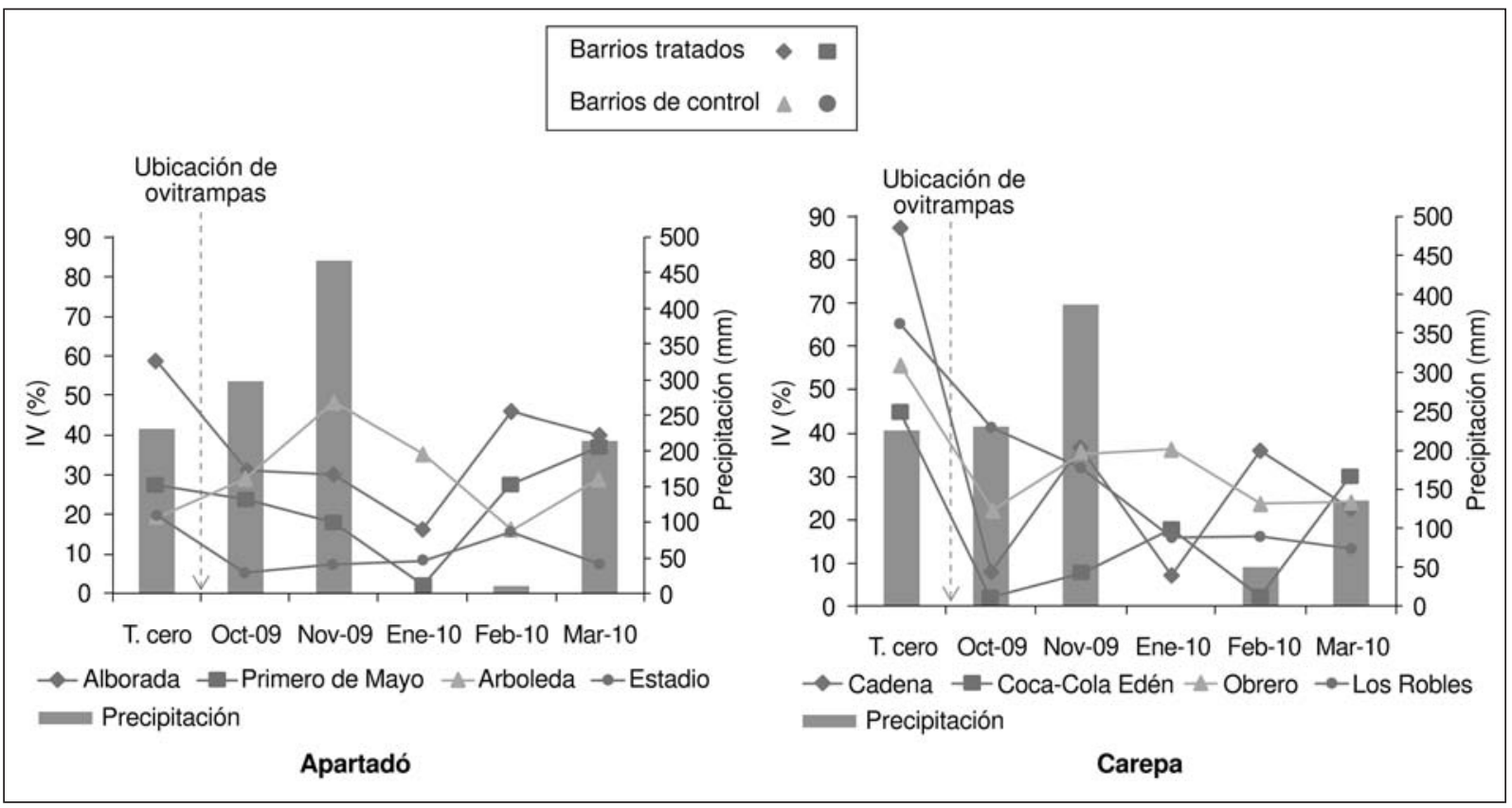

Figura 6. Variación temporal de los índices de infestación de adultos en los barrios de Apartadó y Carepa, ambos estudiados. La gráfica se presenta en escala logarítmica debido al rango de valores (mínimo, 0 , y máximo, 87,3). A los valores de 0 se les asignó el valor de 1 .

más altos de todos los índices calculados, siendo el barrio Cadena el de mayor incidencia de infestación por $A$. aegypti. Durante el estudio, se revisaron 8.838 depósitos, de los cuales, 502 eran positivos para larvas o pupas de $A$. aegypti. En todos los muestreos, la categoría de recipiente más frecuente fue la de tanques bajos (22\%), de los cuales el $15,1 \%$ presentaba larvas o pupas de A. aegypti (cuadro 4).

La cantidad de recipientes por municipio fue de 4.511 en Carepa y de 4.327 en Apartadó, con un promedio de 4,1 y 2,1 recipientes por vivienda, respectivamente.

El barrio que presentó el mayor índice de infestación de viviendas en el municipio de Apartadó en el tiempo cero (antes de la intervención), fue La Alborada (58,82 \%); el barrio Primero de Mayo presentó el valor más bajo $(1,92)$ en el mes de enero. En el análisis estadístico se encontraron diferencias significativas entre los índices de vivienda (Friedman $=6,33 ; p<0,05$ ) de los barrios tratados y los de control. En el municipio de Carepa, el barrio Cadena presentó el índice más alto de infestación de viviendas en el tiempo cero (87,3\%), y el más bajo lo presentó el barrio CocaCola Edén $(4,34 \%)$ en el mes de octubre (figura 3). Se observó que todos los barrios intervenidos
Cuadro 4. Descripción de los depósitos inspeccionados y los depósitos positivos en Apartadó y Carepa, octubre 2009 - marzo 2010

\begin{tabular}{lrrrr}
\hline \multirow{2}{*}{ Tipo de depósito } & \multicolumn{2}{c}{ Apartadó } & \multicolumn{2}{c}{ Carepa } \\
\cline { 2 - 5 } & Cantidad & Positivos & Cantidad & Positivos \\
\hline Tanques bajos & 1.013 & 157 & 927 & 136 \\
Tanques elevados & 242 & 2 & 130 & 0 \\
Canecas & 740 & 66 & 1.011 & 54 \\
Llantas & 136 & 15 & 163 & 18 \\
Botellas & 1.028 & 3 & 934 & 9 \\
Floreros & 390 & 13 & 303 & 12 \\
Otros & 778 & 9 & 1.043 & 8 \\
Total & $\mathbf{4 . 3 2 7}$ & $\mathbf{2 6 5}$ & $\mathbf{4 . 5 1 1}$ & $\mathbf{2 3 7}$ \\
\hline
\end{tabular}

presentaron los índices de vivienda más altos en el tiempo cero y que tales índices disminuyeron después de la colocación de las ovitrampas. Sin embargo, en los dos últimos meses del estudio (febrero y marzo), los barrios tratados presentaron nuevamente los índices de vivienda más altos. No se encontraron diferencias significativas en los índices de viviendas de los barrios de Carepa.

En el municipio de Apartadó, el barrio que presentó el valor más alto del índice de infestación de depósitos fue La Alborada (58,82 \%) en el tiempo cero, en tanto que el barrio Arboleda presentó el valor más bajo $(0,49 \%)$ en el mes de enero. En 
los barrios intervenidos se hallaron los valores más altos durante todos los meses de muestreo, con excepción del mes de noviembre, cuando el barrio Arboleda tuvo el valor más alto. Se encontraron diferencias significativas entre los índices de depósitos del barrio intervenido Primero de Mayo y los barrios de control (Friedman=7,0; $p<0,05$ ).

En el municipio de Carepa, el barrio Obrero presentó el valor más alto para este índice en el tiempo cero $(82,7 \%)$, y el más bajo lo presentó el barrio Coca-Cola Edén (1,77\%) en el mes de febrero (figura 3). Antes de la intervención, los barrios intervenidos presentaban los índices de depósitos más bajos comparados con los de los barrios de control, pero después de colocar las ovitrampas el comportamiento de este índice fue variable, sin presentar tendencia en el tiempo (Friedman $=3,0 ; p>0,05)$. Para el último mes de muestreo, el valor del índice de infestación de depósitos de los barrios tratados fue mayor que en los barrios de control $(13,16$ Vs. 7,1$)$.

En el municipio de Apartadó, el barrio que presentó el valor más alto del índice de Breteau en el tiempo cero fue La Alborada $(111,8)$, mientras que el barrio Arboleda presentó el más bajo $(2,1)$ en el mes de enero. Después de colocar las ovitrampas se observó una reducción notable de este índice tanto en los barrios intervenidos como en los barrios de control (figura 5). Sin embargo, los valores del índice de Breteau en los barrios tratados siempre fueron superiores a los valores de los barrios de control. Se encontraron diferencias significativas entre el índice de Breteau del barrio La Alborada (intervenido) y el de los barrios de control (Friedman=7,0; $p<0,05$ ). En el municipio de Carepa, uno de los barrios de control, el barrio Obrero presentó el valor más alto para este índice en el tiempo cero $(337,9)$, seguido por uno de los barrios intervenidos, el barrio Cadena, con un valor de 141,8; el valor más bajo $(6,5)$ lo presentaron los barrios Coca-Cola Edén en octubre y Cadena en enero. Durante la intervención se logró una disminución importante en este índice, pero para marzo los barrios intervenidos presentaron valores superiores a los de los barrios de control.

En el tiempo cero, el barrio del municipio de Apartadó que presentó el valor más alto del índice de adultos fue La Alborada (39,2\%), y en el municipio de Carepa, el barrio Cadena (87,3\%). Debe señalarse que este valor fue más alto en todos los barrios en el mes anterior a la intervención (tiempo cero) y que en algunos meses fue de cero, lo que indica que no había presencia de adultos en estos meses en las viviendas (figura 6).

En los barrios del municipio de Carepa no se encontraron diferencias significativas en los índices estudiados entre los barrios intervenidos y los de control durante este periodo de estudio.

\section{Uso de ovitrampas para la vigilancia de Aedes aegypti}

Se hicieron 3.114 revisiones de las 519 ovitrampas ubicadas en los barrios intervenidos; de estas, 2.380 (76,4\%) fueron positivas para huevos de $A$. aegypti. Durante los seis meses de recolección de huevos se contaron 501.425 huevos y el promedio por mes de muestreo fue de 211 huevos por ovitrampa.

En el municipio de Apartadó, el total de revisiones fue de 2.010, de las cuales, el 72,2 \% fue positivo; se recolectaron 311.919 huevos de $A$. aegypti. Los valores del índice de densidad de huevos en Apartadó fluctuaron entre 180,2 y 374 huevos por ovitrampa, con un promedio de 214,9 huevos por ovitrampa (DE $\pm 53,5)$. El barrio Primero de Mayo presentó el índice más alto en octubre (374 huevos/ ovitrampa) (figura 7).

En el municipio de Carepa, el total de revisiones fue de 1.104 , de las cuales, $84,1 \%$ fue positivo. Se recolectaron 189.506 huevos, con un promedio por mes de muestreo de 203,9 huevos por ovitrampa. Los valores del índice de densidad de huevos fluctuaron entre 119,08 y 338,4 huevos por ovitrampa, con un promedio de 191,4 huevos por ovitrampa (DE $\pm 59,1)$. Durante enero se recolectó en los dos municipios el mayor número de huevos en promedio (255,8 huevos/ovitrampa) y, en noviembre, el menor número (170,6 huevos/ovitrampa).

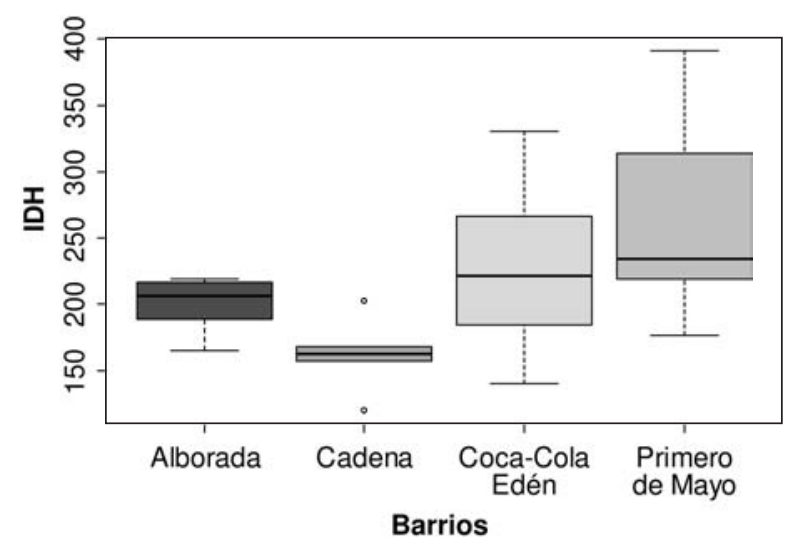

Figura 7. Promedio de huevos en las ovitrampas de los barrios durante el periodo de estudio. IDH: Índice de densidad de huevos 
El máximo número de huevos recolectado en una sola ovitrampa fue de 3.511 en el barrio CocaCola Edén durante el mes de enero. Los índices de ovitrampas positivas fluctuaron entre 47,8 y $74,2 \%$, presentándose los valores más altos en los barrios Cadena y Coca-Cola Edén del municipio de Carepa (figura 8). El barrio Primero de Mayo de Apartadó presentó los valores más bajos de este índice. Los valores de este índice calculados indican que entre 47,8 y $74,2 \%$ de las viviendas de los barrios estudiados fueron visitadas por hembras de $A$. aegypti que depositaron sus huevos en las trampas.

\section{Distribución espacial de Aedes aegypti}

Se generaron mapas de densidad para los barrios La Alborada, Primero de Mayo y Cadena (figuras 9-12). No fue posible hacerlo para el barrio CocaCola Edén debido a que el área del barrio es muy pequeña y contiene algunas zonas de potrero (zonas verdes) que no permitieron conformar conglomerados de densidad de huevos.

\section{Discusión}

Todos los barrios incluidos en este estudio presentaron índices anteriores a la intervención con valores altos (de vivienda: 19,3-87,3 \%; DE $\pm 24,1$; de depósito: 13,6-82,7\%; DE $\pm 26,3$; de Breteau: 22,2-337,9; DE $\pm 102,1$ ), por lo que, de acuerdo con los parámetros de la OMS, se clasificaron como barrios de alta incidencia de infestación por A. aegypti (cuadro 3) (42).
En los dos municipios estudiados se halló que los principales criaderos fueron los tanques bajos y las canecas (cuadro 4). Estos resultados concuerdan con los de López $(45,46)$, quien reportó que en los municipios de Antioquia que carecen de suministro permanente de agua, como Apartadó y Carepa, casi el $50 \%$ de los criaderos son tanques de agua domésticos.

En el municipio de Carepa, los barrios estudiados presentaron una mayor cantidad de criaderos, a pesar de ser barrios con menor número de viviendas y menor densidad de población que los de Apartadó.

En los dos municipios se observó la misma tendencia en cuanto al índice de infestación de viviendas; los índices antes de la intervención eran mayores en los barrios tratados, pero después de colocar las ovitrampas disminuyeron, resultado indicativo de que, probablemente, las ovitrampas tuvieron efecto sobre estos índices. Sin embargo, en los dos últimos meses del estudio (febrero y marzo) los barrios intervenidos presentaron los valores más altos de dichos índices, lo que coincidió con un aumento en la precipitación de la zona (figura 3); este resultado difirió del encontrado en los barrios de control, lo cual puede deberse a que en los primeros el programa de control de vectores de la Dirección Seccional de Salud de Antioquia estuvo interrumpido de enero a marzo, por lo que las ovitrampas fueron la única estrategia de control de las poblaciones del mosquito durante esos tres meses.

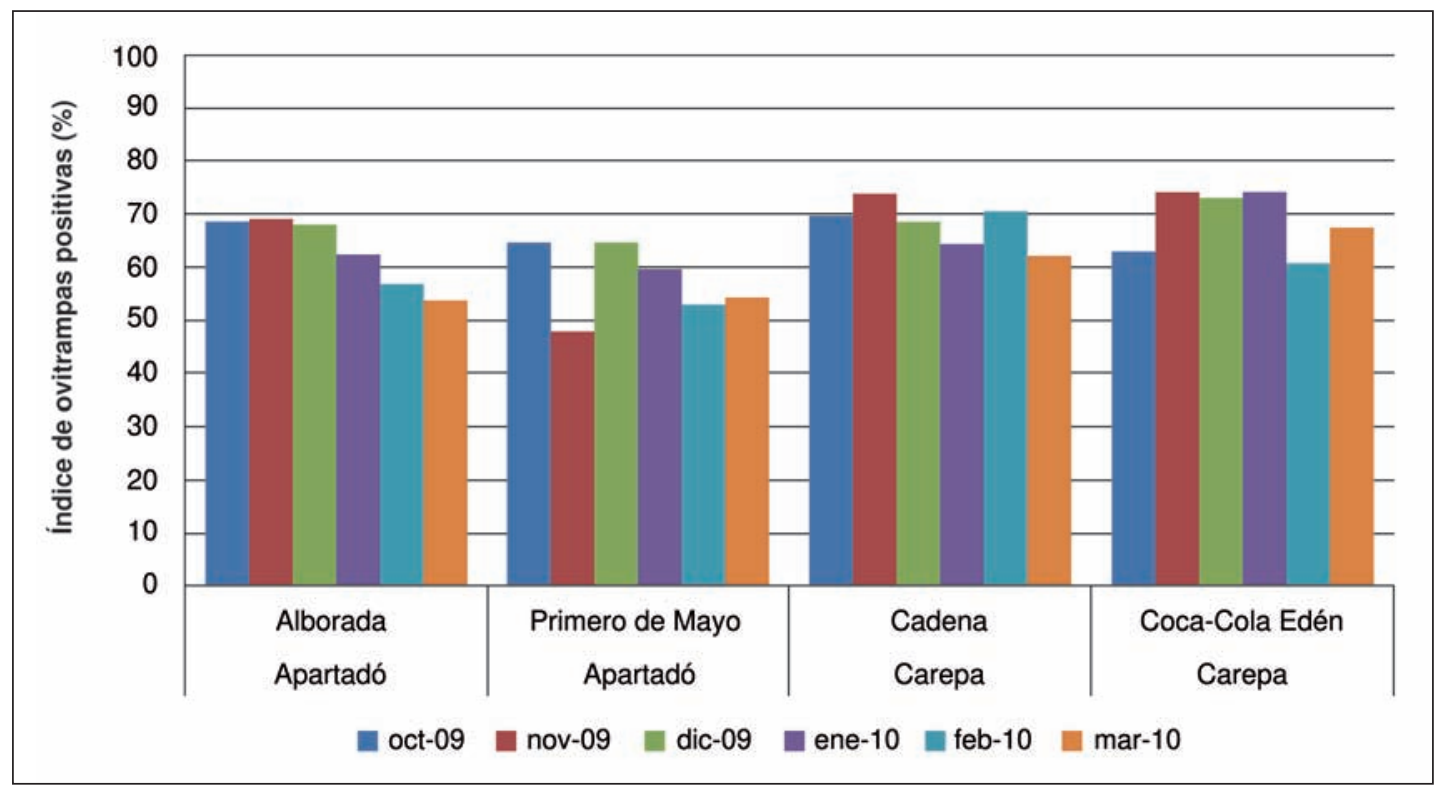

Figura 8. Índice de ovitrampas positivas en los barrios intervenidos durante el periodo de estudio 

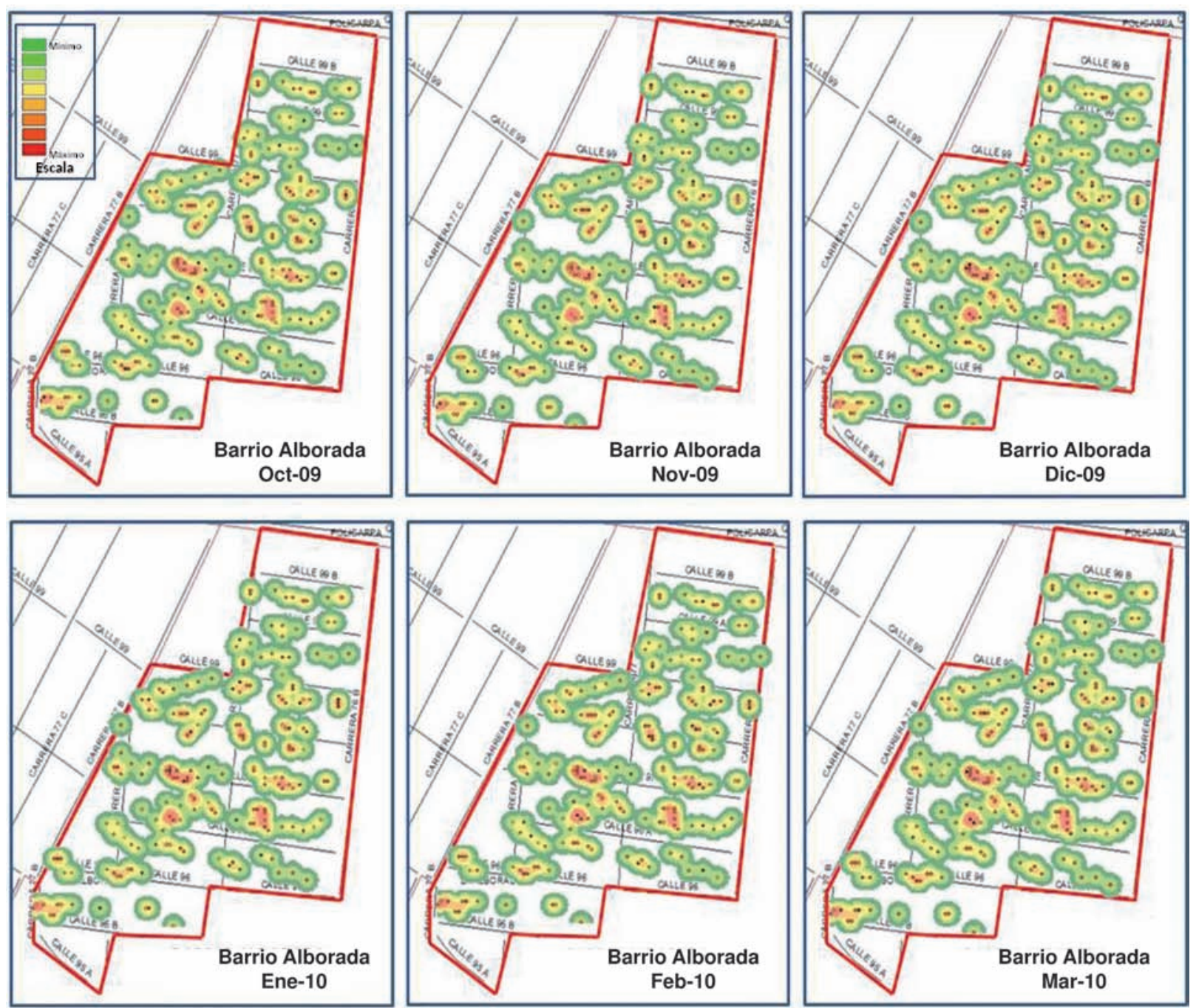

Figura 9. Mapas de densidad de Kernel que muestran las áreas con puntos críticos por la densidad de huevos de Aedes aegypti en el barrio La Alborada, Apartadó

En cuanto a los índices de depósitos, estos no presentaron ninguna tendencia en el tiempo, pero sí se encontró una diferencia significativa entre los barrios intervenidos y los de control en Apartadó (Friedman=7,0; $\mathrm{p}<0,05)$. El índice de adultos presentó en la mayoría de los casos un valor de cero, lo que indica que las ovitrampas no tuvieron efecto sobre este índice. El índice de Breteau, a pesar de presentar una reducción importante después de la intervención, no pareció verse afectado por las ovitrampas, ya que no se observó disminución en los barrios intervenidos.

En el municipio de Apartadó se encontraron diferencias significativas en los índices tradicionales (de viviendas, de depósitos y de Breteau) entre los barrios intervenidos y los barrios de control, lo que indica que las ovitrampas tuvieron efecto sobre estos índices. Sin embargo, no se obtuvo el mismo resultado en los barrios del municipio de Carepa, lo que probablemente se debe a que el número de recipientes "competía" con las ovitrampas; en este municipio la relación de recipientes y vivienda fue de 4,08 y, en Apartadó, de 2,1. En estudios llevados a cabo en Brasil y Tahilandia se demostró que la eficacia de las ovitrampas se reducía en los lugares con mayor cantidad de sitios en competencia con las ovitrampas para la oviposición de las hembras $(29,30)$.

En Tailandia, Sithiprasasna, et al., (30) evaluaron ovitrampas letales para el control de $A$. aegypti y encontraron que tienen un efecto significativo en la reducción de las poblaciones del vector, pero 


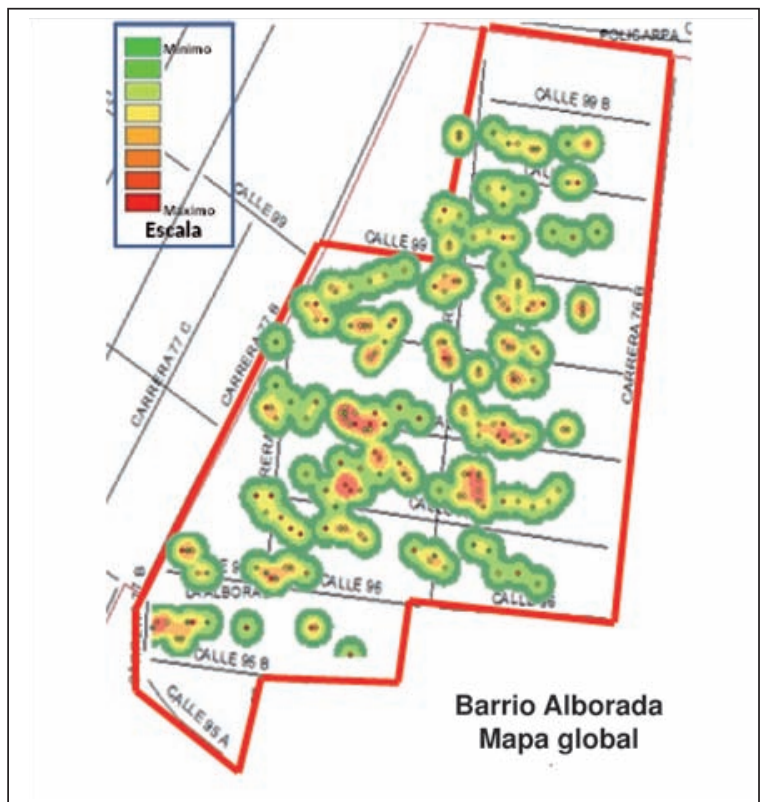

Figura 10. Mapa global de densidad de Kernel que muestra las áreas con puntos críticos por la densidad de huevos de Aedes aegypti en el barrio La Alborada, Apartadó

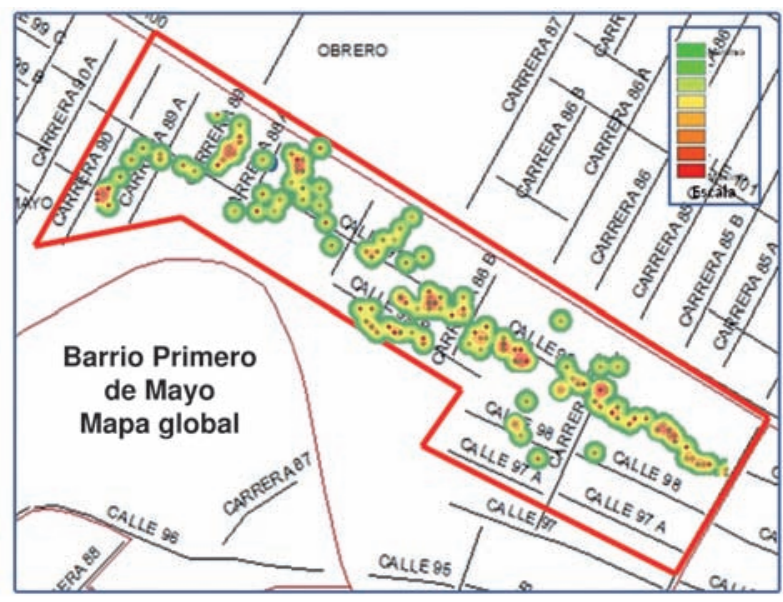

Figura 11. Mapa global de densidad de Kernel que muestra las áreas con puntos críticos por la densidad de huevos de Aedes aegypti en el barrio Primero de Mayo, Apartadó

que su eficacia en el sector estudiado disminuía, principalmente por el alto número de sitios alternativos de oviposición.

Perich, et al., (29) demostraron en su estudio que es necesario evaluar las ovitrampas durante un periodo más largo en sitios con mayor cantidad de criaderos, para disminuir las poblaciones de $A$. aegypti. Sin embargo, en dicho estudio se utilizaron diez trampas por vivienda, mientras que en este se utilizó una sola trampa por vivienda.

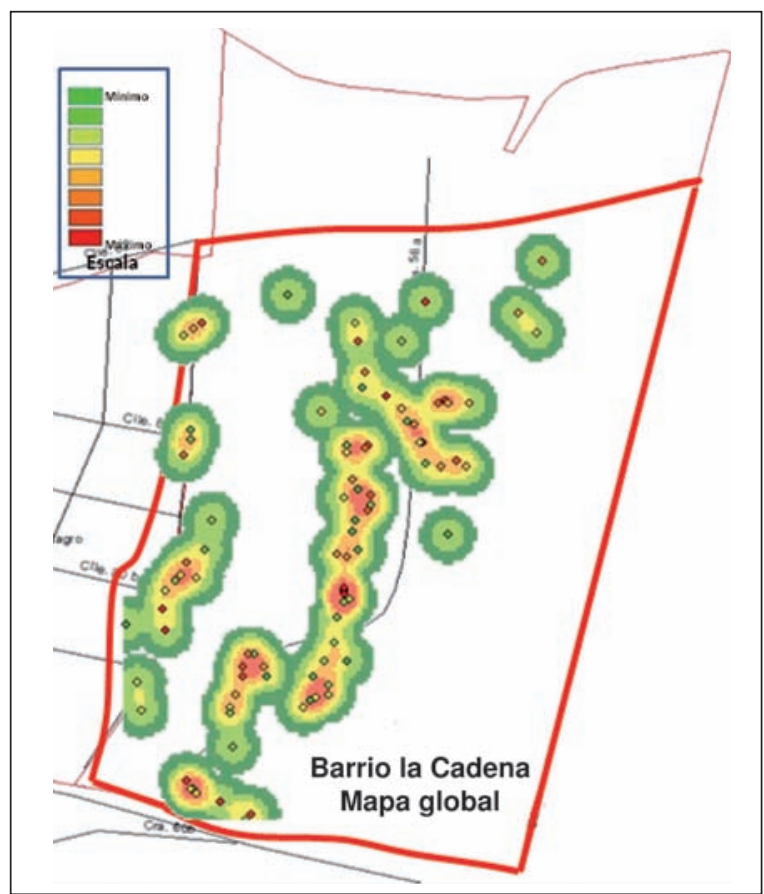

Figura 12. Mapa global de densidad de Kernel que muestra las áreas con puntos críticos por la densidad de huevos de Aedes aegypti en el barrio La Cadena, Carepa

Los resultados de este estudio respaldan la sugerencia hecha por los autores citados, Perich, et al., (29) y Sithiprasasna, et al., (30), de usar las ovitrampas como parte de los programas integrados de control, pero haciendo énfasis en la reducción de los hábitats larvales aledaños a las trampas.

Otros autores como Cheng, et al., (47), registran que el uso de ovitrampas modificadas redujo el índice de Breteau en $36 \%$ en las áreas intervenidas, en tanto que en las no intervenidas este índice aumentó en $500 \%$. Sin embargo, en dicho estudio el uso de ovitrampas se acompañó con la remoción de criaderos.

En un estudio en Brasil, Acioli (33) reportó una mayor sensibilidad de las ovitrampas para determinar la infestación por $A$. aegypti que la obtenida con los índices larvarios tradicionales e informó que, cuando el índice de infestación de depósitos era de $1 \%$, el índice de ovitrampas positivas era de $85 \%$. En nuestro estudio se encontró que, en algunos casos, cuando el índice de infestación de depósitos era de 1,3\%, el índice de ovitrampas positivas era de $60,7 \%$.

Los resultados de esta investigación contrastan con los reportados por Ocampo, et al., (13) en un estudio en Cali, Colombia, en el cual se evaluaron 
estrategias comunitarias para el control de $A$. aegypti, incluida la colocación de ovitrampas. En dicho estudio no se encontraron diferencias significativas entre los barrios intervenidos y los de control, por lo que se concluyó que las actividades educativas, así como las visitas periódicas a las casas, lograban reducciones similares de los estados inmaduros y adultos de $A$. aegypti.

En cuanto al índice de ovitrampas positivas, este presentó valores muy altos, lo que indica una gran infestación por $A$. aegypti en los barrios intervenidos.

Al comparar los valores de este índice con los tradicionales de viviendas y de Breteau, se puede observar que durante los meses de muestreo, los valores del índice de ovitrampas positivas fueron superiores en todos los barrios. En el barrio Cadena se encontró que, mientras el índice de infestación de viviendas presentó valores de riesgo bajos en octubre y enero, el índice de ovitrampas positivas fue superior a $60 \%$. En cuanto al índice de Breteau, este evidenció un bajo riesgo de infestación durante el mes de enero en los barrios Cadena y Coca-Cola Edén, contrastando con el índice de ovitrampas positivas, que fue superior a $60 \%$ en el mismo periodo. Este resultado concuerda con los obtenidos por Chau-Mei Ho, et al., (48) en Taiwán, quienes hallaron que el índice de ovitrampas es más sensible que el de Breteau para determinar la presencia de $A$. aegypti.

Al comparar el índice de ovitrampas positivas con el de infestación de depósitos, se puede apreciar que, a partir de la primera evaluación, este último disminuyó en todos los barrios, tanto intervenidos como de control, pero el primero presentó valores muy altos en todos los meses de muestreo. Este resultado demuestra que el índice de ovitrampas positivas es más informativo que el de infestación de depósitos, a la hora de comparar el riesgo de infestación de $A$. aegypti.

En este estudio se observó un número variable en el índice mensual de densidad de huevos entre los barrios, resultado que puede deberse a las condiciones intrínsecas de cada barrio. Algunos barrios presentaron mayor cantidad de criaderos de A. aegypti que otros y, por lo tanto, la competencia por los sitios de oviposición fue menor. Un resultado similar encontraron Chau-Mei Ho, et al., (48) en lo concerniente a la variación de $A$. aegypti en las ovitrampas de las áreas de estudio, por lo cual concluyeron que hay otros sitios de oviposición que le hacen competencia a las ovitrampas y, en consecuencia, la probabilidad de que las hembras depositen los huevos en la trampa es diferente de un sitio a otro.

El índice de densidad de huevos fue más alto en el barrio Primero de Mayo, con un promedio de 256 huevos por ovitrampa. Si se asume una relación directa entre el número de huevos y la densidad de hembras de $A$. aegypti, se podría inferir que en este barrio hubo mayor cantidad de mosquitos que en los otros barrios estudiados. Es de resaltar que este barrio es el de mayor densidad de población humana. Este resultado concuerda con los de Regis, et al., (31) y Franco-Estrada, et al., (49), quienes registraron mayor densidad de huevos en las áreas con más alta densidad de población humana, lo que sugiere que la infestación con $A$. aegypti ocurre más rápidamente en áreas con mayor densidad demográfica.

El índice de densidad de huevos más bajo se presentó en el barrio La Cadena, con un promedio de 170,9 huevos por ovitrampa, resultado que pudo haberse debido a la menor densidad de población humana en ese barrio y a sus condiciones semiurbanas, pues está localizado a mayor distancia de la cabecera municipal. Un resultado similar obtuvieron Regis, et al., (31) en Recife, Brasil, donde este índice fue más bajo en el barrio con menor densidad demográfica, ubicado en la periferia de la ciudad cerca de una zona boscosa.

En este estudio se encontró que los índices de ovitrampas positivas y de densidad de huevos son mejores indicadores de la tasa de infestación por $A$. aegypti, que los de vivienda y de Breteau, de forma similar al hallazgo de Morato, et al., (36) al comparar la infestación por $A$. aegypti medida con ovitrampas y la medida con los índices tradicionales en el norte de Brasil.

En algunos estudios previos se ha tratado de determinar la relación entre la densidad de huevos y la densidad de adultos en áreas determinadas. Dibo, et al., (50) relacionaron la densidad de huevos, la densidad de adultos, los casos de dengue y los factores climáticos en Sao Paulo, Brasil, y encontraron que la densidad de huevos no era un indicador muy eficiente para determinar el riesgo de presentación de casos de la enfermedad, pero sí era muy sensible para determinar la presencia de adultos de $A$. aegypti en zonas de baja infestación; además, estos autores hallaron que, durante el periodo del estudio, la densidad de huevos estuvo relacionada con la densidad de adultos (50). También, en Recife, Regis, et al., (31) hallaron 
que la densidad de huevos era un indicador para determinar las zonas con altas concentraciones de adultos de $A$. aegypti y con más alto riesgo de casos de dengue.

Teniendo en cuenta los hallazgos de estos autores, podemos decir que según los índices de ovitrampas positivas y de densidad de huevos hallados en este estudio, los barrios intervenidos presentaban un alto riesgo de infestación por $A$. aegypti, riesgo que no se pudo determinar con los índices tradicionales, como el de depósitos y el de Breteau.

Se observó que durante el periodo de estudio, los indicadores entomológicos de infestación por $A$. aegypti se mantuvieron en niveles de riesgo medio o alto tanto en los barrios intervenidos como en los barrios de control, a pesar de que el programa de control gubernamental para este vector operó en todos los barrios en los tres primeros meses de implementación de este modelo. Este resultado demuestra que el programa de control vectorial establecido por el gobierno en esta zona no es muy eficiente, en parte debido a que los funcionarios encargados no tienen continuidad laboral y, por lo tanto, no se puede establecer el riesgo ni llevar a cabo actividades de control en algunas épocas del año. En los municipios de Apartadó y Carepa se le hace seguimiento al vector del dengue por medio de tres índices tradicionales (de viviendas, de depósitos y de Breteau); sin embargo, estos índices no son los más adecuados para determinar el riesgo de infestación, ya que no toman en cuenta la densidad de larvas y pupas, considerando de igual riesgo un recipiente con una larva que un recipiente con 1.000 larvas.

Entre las limitaciones del presente estudio podemos mencionar el hecho de que el periodo de evaluación de las ovitrampas fue muy corto (seis meses), lo cual podría explicar por qué no se logró verificar la eficacia de las ovitrampas en la reducción significativa de la infestación por $A$. aegypti, lo que sí se ha observado en otros estudios, como el de Regis, et al., (31), implementado en Brasil y evaluado durante dos años consecutivos. Según estos autores (31), una estrategia integrada, como la eliminación de huevos por medio de ovitrampas y el uso de larvicidas biológicos como $B$. thuringiesis var. israeliensis en los depósitos de agua que sirven como criaderos, puede ser una estrategia promisoria de control.

Durante este estudio se logró eliminar cerca de 502.000 huevos de $A$. aegypti en los barrios intervenidos, número importante si tenemos en cuenta que un porcentaje de estos hubiese logrado llegar a la fase adulta y convertirse en posibles vectores de dengue en la zona.

En los seis meses de evaluación se determinaron los puntos críticos de infestación por $A$. aegypti con base en la densidad de huevos en los barrios estudiados. A pesar de ser una escala pequeña (barrio), se pudieron identificar áreas donde se deben intensificar las actividades de control. Se reconocieron los puntos críticos para tres de los barrios estudiados, en los cuales se encontró en todos los meses de evaluación las mismas viviendas o viviendas muy cercanas. Esto pudo deberse a que en estas viviendas había condiciones favorables para la reproducción de los mosquitos, evidenciándose la poca dispersión de las hembras en dichos sitios. Estos resultados confirman la hipótesis de que las hembras con condiciones óptimas de disponibilidad de alimento y con sitios adecuados de ovipostura, tienen un rango de vuelo estimado de $100 \mathrm{~m}$, lo que limita sus visitas a dos o tres casas durante toda su vida (40).

Los resultados obtenidos en el presente estudio demuestran que, en el Urabá antioqueño, las ovitrampas con $B$. thuringiesis var. israeliensis sirven como herramientas de vigilancia y control de $A$. aegypti. En futuros estudios sería importante sumar el uso de ovitrampas a las estrategias integradas de control, colocándolas en un área mayor y reduciendo los criaderos, así como desarrollar campañas educativas de promoción y divulgación de información sobre la enfermedad.

\section{Agradecimientos}

A Cástor Guisande, por la asesoría en el procesamiento estadístico de los datos, a Ridelane Veiga Acioli, por su valiosa contribución en la asesoría de este trabajo, a la comunidad de los barrios estudiados, a la Dirección Seccional de Salud de Antioquia, al Instituto Colombiano de Medicina Tropical y a Colciencias, por la financiación del proyecto 3256-04-18067.

\section{Conflicto de intereses}

Los autores de este estudio declaran que no hay conflicto de intereses.

\section{Financiación}

Este estudio fue financiado por el Instituto Colombiano de Medicina Tropical y Colciencias, código 3256-04-18067. 


\section{Referencias}

1. Kyle J, Harris E. Global spread and persistence of dengue. Annu Rev Microbiol. 2008;62:71-92. http:/dx.doi. org/10.1146/annurev.micro.62.081307.163005

2. Halstead S. Dengue virus-mosquito interactions. Annu Rev Entomol. 2008;53:273-91. http:/dx.doi.org/10.1146/annurev. ento.53.103106.093326

3. Badii MH, Landeros J, Cerna E, Abreu JL. Ecología e historia del dengue en las Américas. Daena: Int J Good Conscience. 2007;2:248-73. Fecha de consulta: 10 de febrero de 2013. Disponible en: http://www.spentamexico. org/v2-n2/2(2)\%20248-273.pdf.

4. Ministerio de la Protección Social, Organización Panamericana de Salud, Instituto Nacional de Salud. Guía de gestión para la vigilancia entomológica y control de la transmisión de dengue. Plan Nacional de Salud Pública. Bogotá D.C.: Ministerio de la Protección Social; 2010.

5. Rodhain F. Données recents sur l'épidémiologie de l'encéphalite japonaise. Bull Acad Natl Med. 1996;180: 1325-40.

6. Gubler DJ. The emergence of epidemic dengue fever and dengue hemorrhagic fever in the Americas: A case of failed public health policy. Rev Panam Salud Pública. 2005;17:221-4. http://dx.doi.org/10.1590/S102049892005000400001

7. Morrison AC, Sihuincha M, Stancil JD, Zamora E, Astete $\mathbf{H}$, Olson JG, et al. Aedes aegypti (Diptera: Culicidae) production from non-residential sites in the Amazonian city of Iquitos, Peru. Ann Trop Med Parasitol. 2006;100:73-86.

8. Domínguez MA. Evaluación de ovitrampas como sistema de vigilancia entomológica en sitios públicos de Chetumal, Quintana Roo (tesis). Nuevo León: Universidad Autónoma de Nuevo León; 2010. p. 1-50.

9. Niño L. Interpolación espacial de la abundancia larval de Aedes aegypti para localizar focos de infestación. Rev Panam Salud Pública. 2011;29:416-22. http://dx.doi. org/10.1590/S1020-49892011000600006

10. Barreto F, Teixeira MG, Nascimento N, Carvalho M, Barreto ML. Spread pattern of the first dengue epidemic in the city of Salvador, Brazil. BMC Public Health. 2008;8:51. http://dx.doi.org/10.1186/1471-2458-8-51

11. Teixeira MG, Nascimento N, Barreto M, Mota E. Dengue and dengue hemorrhagic fever epidemics in Brazil: What research is needed based on trends, surveillance, and control experiences? Cad Saúde Pública. 2005;21:1307-15. http://dx.doi.org/10.1590/S0102-311X2005000500002

12. Marquetti M, Valdéz V, Aguilera L, Navarro A. Vigilancia entomológica de Aedes aegypti y otros culícidos en ciudad de la Habana, Cuba, 1991-1996. Rev Cubana Med Trop. 2000;52:133-7.

13. Ocampo CB, González C, Morales CA, Pérez M, Wesson D, Apperson $\mathrm{CH}$. Evaluation of community-based strategies for Aedes aegypti control inside houses. Biomédica. 2009;29: 282-97.

14. Spiegel J, Bennett S, Hattersley L, Hayden M, Kittayapong P, Nalim S, et al. Barriers and bridges to prevention and control of dengue: The need for a social-ecological approach Ecohealth. 2005;2:273-90. http://dx.doi.org/10.1007/s10393005-8388-x
15. Guzmán MG, Kouri G. Dengue: An update. Lancet Infect Dis. 2002;2:33-42.

16. SIVIGILA. Boletín epidemiológico. Dengue, semana 6 de 2013. Grupo funcional ETV. Bogotá: Instituto Nacional de Salud; 2013. p. 1-5.

17. Dirección Seccional de Salud de Antioquia. Estadística de eventos de Salud Pública. Enfermedades transmitidas por vectores 2000-2010 por municipio. Fecha de consulta: 10 de febrero de 2013. Disponible en: http://www.dssa. gov.co/index.php/estadisticas/eventos-en-salud-publica.

18. Hopp MJ, Foley JA. Global-scale relationship between climate and the dengue fever vector Aedes aegypti. Clim Change. 2001;48:411-63. http://dx.doi.org/10.1023/ A:1010717502442

19. Guzmán M, Kourí G, Díaz M, Llop A, Vázquez S, González $\mathrm{D}$, et al. Dengue, one of the great emerging health challenges of the 21 st century. Expert Rev Vaccines. 2004;3:511-20.

20. López C, Lazo L, Gil L, Hermida L, Guillén G, Guzmán $\mathbf{G}$, et al. New evidence on the virus capsid as a vaccine candidate against the Dengue 2 virus without the induction of the neutralizing antibodies. Biotecnología Aplicada. 2008;25:54-5.

21. Georghiou GP, Wirth M, Tran H, Saume F, Knudsen AB. Potential for organophosphate resistance in Aedes aegypti (Diptera: Culicidae) in the Caribbean area and neighboring countries. J Med Entomol. 1987;24:290-4.

22. Mekuria Y, Gwinn TA, Williams DC, Tidwell MA. Insecticide susceptibility of Aedes aegypti from Santo Domingo, Dominican Republic. J Am Mosq Control Assoc. 1991;7:69-72.

23. Mazzarri MB, Georghiou GP. Characterization of resistance to organophosphate, carbamate, and pyrethroid insecticides in field populations of Aedes aegypti from Venezuela. J Am Mosq Control Assoc. 1995;11:315-22.

24. Rawlins SC, Wan JO. Resistance in some Caribbean populations of Aedes aegypti to several insecticides. J Am Mosq Control Assoc. 1995;11:59-65.

25. Brown AW. Insecticide resistance in mosquitoes: A pragmatic review. J Am Mosq Control Assoc. 1986;2:123-40.

26. Michigan State University. Arthropod Pesticide Resistance Database. Fecha de consulta: $1^{\circ}$ de septiembre de 2012. Disponible en: http://www.pesticideresistance.org/display. php?page $=$ species $\&$ arld $=7$.

27. Vargas M. Uso de ovitrampas en los programas de prevención y control del dengue. Rev Col MQC de Costa Rica. 2002;8:122-3.

28. Villaseca $\mathbf{P}$, Cáceres $\mathbf{A}$, Linares $\mathbf{N}$. Eficacia de las ovitrampas para la detección rápida de Aedes aegypti en Chanchamayo (Junín) y Pucallpa (Ucayali), Perú. Serie de Informes técnicos No. 54. Lima; Ministerio de Salud, Instituto Nacional de Salud, Centro de Información y Documentación Científica; 2004.

29. Perich MJ, Kardec A, Braga IA, Portal IF, Burge R, Zeichner BC, et al. Field evaluation of a lethal ovitrap against dengue vectors in Brazil. Med Vet Entomol. 2003;17:205-10. http://dx.doi.org/10.1046/j.1365-2915.2003. 00427.x 
30. Sithiprasasna R, Pradith M, Noigamol Ch, Perich MJ, Zeichner BC, Burge B, et al. Field evaluation of a lethal ovitrap for the control of Aedes aegypti (Diptera: Culicidae) in Thailand. J Med Entomol. 2003;40:455-62.

31. Regis L, Monterior AM, Varial MA, Silveira JC Jr, Furtado AF, Acioli RV, et al. Developing new approaches for detecting and preventing Aedes aegypti population outbreaks: Basis for surveillance, alert and control system. Mem Inst Oswaldo Cruz. 2008;103:50-9. http://dx.doi.org/10. 1590/S0074-02762008000100008

32. Santos SR, Melo-Santos M, Regis L, Albuquerque CM. Field evaluation of ovitraps consociated with grass infusion and Bacillus thuringiensis var. israelensis to determine oviposition rates. Dengue Bull. 2003;27:156-62.

33. Stoops CA. Influence of Bacillus thuringiensis var. israelensis on oviposition of Aedes albopictus (Skuse). J Vector Ecol. 2005;30:41-4.

34. Braga IA, Gomes AC, Nelson M, Mello RC, Bergamaschi DP, Pacheco JM. Comparação entre pesquisa larvária e armadilha de oviposição, para detecção de Aedes aegypti. Rev Soc Bras Med Trop. 2000;33:347-53. http://dx.doi. org/10.1590/S0037-86822000000400003

35. Ordóñez-González JG, Mercado-Hernández R, FloresSuárez AE, Fernández-Salas I. Use of sticky ovitraps to estimate dispersal of Aedes aegypti in northeastern México. J Am Mosq Control Assoc. 2001;17:93-7.

36. Morato V, Teixeira MG, Gomes AC, Bergamashi DP, Barreto M. Infestation of Aedes aegypti estimated by oviposition traps in Brazil. Rev Saúde Pública. 2005;39:553-8. http://dx.doi.org/10.1590/S0034-89102005000400006

37. Alcaldía de Apartadó. Apartadó, Antioquia, Colombia. Fecha de consulta: $1^{\circ}$ de febrero de 2012. Disponible en: www.apartado-antioquia.gov.co/.

38. Alcaldía de Carepa. Carepa, Antioquia, Colombia. Fecha de consulta: $1^{\circ}$ de febrero de 2012. Disponible en: www. carepa-antioquia.gov.co/.

39. Acioli RV. O uso de armadilhas de oviposição (ovitrampas) como ferramenta para monitoramento populacional do Aedes spp. em bairros do Recife (tesis). Recife, Brasil: Centro de Pesquisa Aggeu Magalhães, Fundação Oswaldo Cruz; 2006.
40. Organización Panamericana de la Salud. Dengue y dengue hemorrágico en las Américas: guías para su prevención y control. Washington D.C.: OPS; 1995.

41. Escobar JP, López YL, Osorio L, González MC, Wolff MI. Manual para la vigilancia y control de vectores de malaria, dengue, fiebre amarilla, leishmaniasis, enfermedad de Chagas y encefalitis equina venezolana desde el nivel municipal. Medellín: Dirección Seccional de Salud de Antioquia; 1999. p. 150.

42. Dirección Seccional de Salud de Antioquia. Protocolo para la inspección, vigilancia y control de los factores de riesgo ambientales, del consumo, vectores y zoonosis. Dirección de Salud Pública. $2^{2}$ edición. Medellín: Editorial Fundación Ciudad Don Bosco; 2007.

43. Forattini OP. Culicidologia Médica. São Paulo: Universidad de São Paulo; 2002. p. 860.

44. Rueda L. Pictorial keys for the identification of mosquitoes (Diptera: Culicidae) associated with dengue virus transmission. Zootaxa. 2004;589:1-60.

45. López YL. Distribución espacial y hábitats larvarios de Aedes aegypti en el departamento de Antioquia. Rev Col Entomol. 1992;18:63-72.

46. López YL. Vigilancia entomológica de Aedes aegypti en el departamento de Antioquia en 1995. Bol Vect. 1996;7:4-17.

47. Cheng ML, Ho BC, Bartnett RE, Goodwin N. Role of a modified ovitrap in the control of Aedes aegypti in Houston, Texas, USA. Bull WHO. 1982;60:291-6.

48. Chau-Mei H, Chein Ch, Cheng TY. Surveillance for dengue fever vectors using ovitraps at Kaohsiung and Tainan in Taiwan. Formosan Entomol. 2005;25:159-74.

49. Franco-Estrada JG, Craig GB. Biología, relaciones con enfermedades y control de Aedes albopictus. Washington, D.C.: Organización Panamericana de la Salud; 1995.

50. Dibo MR, Chierotti AP, Ferrari MS, Mendonça AL, Chiaravalloti NF. Study of the relationship between Aedes (Stegomyia) aegypti egg and adult densities, dengue fever and climate in Mirassol, state of São Paulo, Brazil. Mem Inst Oswaldo Cruz. 2008;103:554-60. http://dx.doi.org/10.1590/ S0074-02762008000600008 